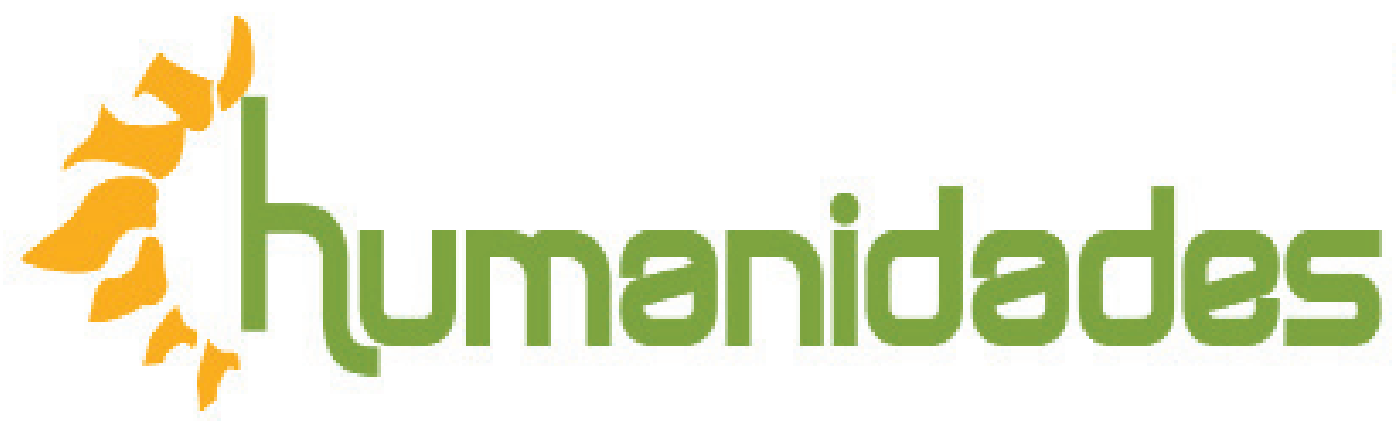

Revista de la Escuela de Estudios Generales, Universidad de Costa Rica

Enero-julio, 2019 •Volumen 9, número 1 • EISSN 2215-3934 • pp. 1-34

Recibido: 18-Setiembre-2018 Aceptado: 9-Noviembre-2018

\title{
Una historia conceptual de los metalenguajes
}

DOI: https://doi.org/10.15517/h.v9i1.35342

\section{Juan Antonio González de Requena Farré}

Licenciado en Filosofía y Letras. Académico de la Universidad Austral de Chile, Chile.

Correo electrónico: jgonzalez@spm.uach.cl

Todos los derechos reservados. Universidad de Costa Rica. Esta revista se encuentra licenciada con Creative Commons. Reconocimiento-NoComercial-SinObraDerivada 3.0 Costa Rica. Correo electrónico: humanidades@ucr.ac.cr/ Sitioweb: http: //revistas.ucr.ac.cr/index.php/ humanidades 


\title{
Una historia conceptual de los metalenguajes
}

\section{Resumen}

En esta revisión teórica se traza la trayectoria del léxico metalingüístico en el pensamiento contemporáneo desde los orígenes de la noción de metalenguaje y la asociación de la función metalingüística con el empleo cotidiano del lenguaje hasta la irrupción de términos como metatexto o metadiscurso, que apuntan a cierto enmarcado transtextual y pragmático de la enunciación. Mediante un relato de las problemáticas teóricas en que fue surgiendo el vocabulario metalingüístico, se pone de manifiesto la inevitable dispersión del vocabulario metalingüístico en la teorización contemporánea del lenguaje.

\section{A Conceptual History of Metalanguages}

\begin{abstract}
In this theoretical review, the trajectory of the metalinguistic lexicon in contemporary thought is traced from the origins of the notion of metalanguage and the association of the metalinguistic function with the everyday usage of language, to the irruption of terms such as metatext or metadiscourse, which point to a certain transtextual and pragmatic framing of the enunciation. Through an account of the theoretical problems in which the metalinguistic vocabulary was emerging, the inevitable dispersion of the metalinguistic vocabulary in the contemporary theorization of language becomes evident.
\end{abstract}

Palabras clave: metalenguaje, metacomunicación, metarrepresentación, metadiscurso
Keywords: metalanguage, metacommunication, metarepresentation, metadiscourse 
“¡Cuánta filosofía inconciente [sic] en los redaños del lenguaje! Todavía habrá que remozar la meta-física en la meta-lingüística, que es una verdadera metalógica" (Unamuno, 2007, p. 106).

En la que quizá sea una de las primeras acuñaciones del término (el texto data de 1895), Miguel de Unamuno invocaba cierta metalingüística, aparentemente vinculada al desciframiento y exégesis del sentido de fondo de las palabras. Unamuno introduce el término en una nota a pie de página y no especifica con precisión el contenido del concepto, pero cabría pensar que, en el curso del pensamiento contemporáneo, se ha hecho efectiva cierta forma de metalingüística. Al menos, la teorización del lenguaje de la segunda mitad del siglo XX aparece marcada por la proliferación de todo un meta-vocabulario (de términos forjados con el prefijo meta-) que contiene expresiones como metasemiótica, metalenguaje, metacomunicación, metadiscurso, metarrepresentación, etc. Esta es su historia.

\section{La conceptualización del metalenguaje}

Aunque la historia del concepto de metalenguaje es reciente, la reflexión sobre el metalenguaje tiene un amplio pasado. En efecto, ya San Agustín planteó

el problema de que los signos lingüísticos pueden significarse a sí mismos y designar las cosas significadas (San Agustín, 2003, pp. 100-101). Asimismo, la Escolástica medieval de los siglos XIII y XIV desarrolló toda una doctrina de la suposición — concebida por autores como Shyreswood en tanto que relación de ordenación lógico-semántica de unos conceptos bajo otros- que distinguía la suposición material (esto es, lo que la expresión supone al representarse a sí misma, a su sonido o grafía) y, por otra parte, la suposición formal (o sea, lo que la expresión supone al representar lo significado por ella). A través de la doctrina de las suposiciones, la Escolástica medieval parece haber introducido tácitamente la distinción entre lenguaje y metalenguaje, en la medida en que se asume que los signos no solo pueden representar su designación conceptual (suposición simple) o su referencia individual (suposición personal), sino también la propia expresión significante (suposición material) (Bochenski, 1985, pp. 175-180). 
A pesar de ciertas nociones metalingüísticas precedentes, el concepto de metalenguaje fue explícitamente acuñado en la primera mitad del siglo XX, en el contexto del desarrollo de la lógica simbólica contemporánea $\mathrm{y}$, más específicamente, en la teoría semántica de Alfred Tarski. Como una manera de hacer frente a las paradojas y antinomias en que se enredan los conceptos semánticos en el lenguaje cotidiano, el lógico polaco Tarski (2005, originalmente publicado en 1944) adoptó la estrategia de definir el concepto de verdad en un lenguaje con una estructura exactamente especificada, como los lenguajes formalizados de la lógica, enriquecidos mediante símbolos no lógicos. Solo se pueden evitar antinomias y paradojas de autorreferencia (como la del mentiroso) si asumimos que la definición del término verdadero o de otros conceptos semánticos no puede formularse en un único lenguaje semánticamente cerrado que contenga de modo incoherente las expresiones, los nombres de las expresiones, las definiciones semánticas y sus reglas de uso. Tarski establecía la necesidad de emplear dos lenguajes diferentes al abordar la definición semántica de la verdad: un lenguaje del cual se habla y a cuyas oraciones se aplica la definición de verdad (el lenguaje-objeto) y, por otra parte, un lenguaje en el que hablamos del primero y en cuyos términos se formula la definición de verdad (el metalenguaje).

Según Tarski, los términos lenguaje-objeto y metalenguaje son relativos, de manera que, si ponemos en discusión las definiciones del metalenguaje, este se convierte en lenguaje objeto de un nuevo metalenguaje de orden superior, y puede desplegarse así toda una jerarquía de metalenguajes. La definición semántica de la verdad presupone que el metalenguaje es esencialmente más rico que el lenguajeobjeto, ya que comprende todas las expresiones del lenguaje-objeto, puede nombrar cada una sus oraciones e incorpora términos relativos a la forma de las expresiones del lenguaje objeto, así como términos lógicos. Para Tarski, un metalenguaje lo suficientemente rico está en condiciones de estipular reglas formales de definición que permiten especificar exactamente una definición no equívoca de la verdad (una formulación de una cláusula de equivalencia formal de las oraciones que satisfacen recursivamente la definición) o de otros conceptos semánticos. . En suma, la caracterización lógico-semántica del metalenguaje nos remite a la posibilidad de formalizar un lenguaje con expresiones de un tipo lógico superior al de aquellas expresiones que contiene el lenguaje-objeto (Tarski, 2005, pp. 305-315). 
La irrupción de la noción de metalenguaje (y otros meta-términos afines) en el campo de la lingüística tuvo lugar en los años cuarenta, bajo el auspicio teórico de Louis Hjelmslev. En sus Prolegómenos a una teoría del lenguaje (1971, obra originalmente publicada en 1943), el lingüista danés planteaba la posibilidad de que una semiótica incorporase en uno de sus planos a otra semiótica: una semiótica connotativa sería una semiótica no científica que presenta una semiótica denotativa en su plano de expresión. Por otra parte, un metalenguaje (o una metasemiótica, según Hjelmslev) constituiría una semiótica científica cuyo plano del contenido es una semiótica de la cual trata. En las definiciones axiomáticas que Hejlmslev formuló, ingresan otros términos con el prefijo meta-: la metasemiótica científica sería una metasemiótica que tiene una semiótica científica como objeto, esto es, constituye uno de sus planos; la metasemiología es una metasemiótica científica cuyas semióticas objeto constituyen semiologías (es decir, metasemióticas con una semiótica no científica por objeto). Como se puede apreciar, el proyecto de convertir a la lingüística en un álgebra inmanente conduce a la introducción recursiva de metasemiologías de orden superior con una terminología especial que no solo incorporen términos definicionales de la semiología y términos indefinibles tomados del lenguaje-objeto, sino también términos indefinibles que designen variaciones de orden superior o categorías de variantes e invariantes. Desde la perspectiva del lingüista danés, la propia lingüística se perfila como una metasemiótica o metalenguaje (Hjelmslev, 1971, pp. 160-173).

\section{La cotidianidad del metalenguaje}

En la década de los cincuenta, la noción de metalenguaje (y todo un metavocabulario asociado) se hace presente en el campo de la teoría de la comunicación. En su ensayo Una teoría del juego y de la fantasía (1991, originalmente leído como conferencia en 1954), Gregory Bateson observaba que la comunicación lingüística opera en distintos niveles de abstracción comunicativa: desde el nivel denotativo hasta el nivel metalingüístico (los mensajes explícitos o implícitos sobre el lenguaje) o metacomunicativo (discurso que tematiza explícita o implícitamente la relación entre los interlocutores). 
Se trata de un logro evolutivo crucial, en virtud del cual el organismo deja de responder de modo automático a los indicios afectivos que otra criatura expresa. El organismo reconoce que las señales, tanto las de los otros como las propias, son solo señales que pueden ser falsificadas o corregidas y, entonces, puede acontecer la invención del lenguaje; pero también se hace posible comunicarse en una multiplicidad de niveles comunicativos, desde el denotativo, hasta el metalingüístico y el metacomunicativo.

En ese sentido, Bateson consideraba que lo extraordinario en la evolución del lenguaje humano no consiste en la abstracción o en la generalización; a diferencia de las comunicaciones de otros mamíferos, que se efectúan en términos de los patrones y contingencias de la relación entre los animales (y versan sobre ellos), el lenguaje humano puede realizar una comunicación denotativa gracias a un conjunto de reglas metalingüísticas que rigen la manera en que las palabras y oraciones gramaticales deben referirse a los objetos y a los sucesos. Los seres humanos emplean, pues, un lenguaje orientado primariamente hacia las cosas mediante nombres y proposiciones para indagar las relaciones, pero, además, todos nuestros mensajes metalingüísticos o metacomunicativos enmarcan explícita o implícitamente cualquier mensaje comunicado, de modo que constituyen marcos cognitivos y psicológicos. En suma, en la teoría de la comunicación de Bateson, el metalenguaje y la metacomunicación cumplen una función cognitiva y no son simplemente un nivel superior de comunicación acerca del código o de la relación comunicativa (Bateson, 1991, pp. 205-207).

En un texto titulado El metalenguaje como problema lingüístico (1988, transcripción de un discurso originalmente publicado en 1956), la visión del lenguaje como proceso de comunicación llevó a Roman Jakobson a defender la existencia de una función metalingüística específica que sería parte integrante de nuestras actividades verbales cotidianas (y no solo del discurso científico). Según Jakobson, la función metalingüística del lenguaje concierne a cierto factor del proceso comunicativo - se centra, concretamente, en el código comunicativo - y se ejerce cada vez que empleamos el lenguaje para glosar nuestros significados o verificar si se emplea el mismo código. 
De ese modo, la función metalingüística guarda relación con la traducibilidad de un signo a otros y con la información sobre el significado asignado a las palabras. Tal y como Jakobson concebía la función metalingüística, el metalenguaje resulta inseparable de la adquisición, desarrollo y asimilación creadora de la lengua, los cuales presuponen la interpretación de unos signos lingüísticos por medio de otros de la misma lengua. Por otra parte, existen perturbaciones de la función metalingüística en la afasia que ponen de manifiesto qué consecuencias tiene una deficiencia en la capacidad para construir proposiciones equivalentes y para traducir expresiones. En ese sentido, Jakobson no solo asociaba la función metalingüística a la capacidad de sostener una comunicación de orden superior sobre el código, sino también a la capacidad de traducción intraidiomática e interidiomática, sin las cuales no hay adquisición del idioma natal ni aprendizaje de una segunda lengua. En fin, para Jakobson, la función metalingüística se ejerce latentemente del modo más cotidiano, en la medida en que cualquier mensaje verbal involucra combinaciones selectivas de constituyentes y, por tanto, conlleva el recurso del código como marco de referencia de cualquier proceso de comunicación lingüística (Jakobson, 1988).

También Harald Weinrich — desde la perspectiva de una lingüística del textoha reivindicado la función decisiva del metalenguaje en la comunicación cotidiana. Según planteó Weinrich en De la cotidianidad del metalenguaje (1981, originalmente publicado en 1976), en distintos contextos en que se producen perturbaciones en la comunicación (como el aprendizaje lingüístico, las patologías del habla y el análisis lógico o lingüístico), se precisa de una reflexión sobre el lenguaje mediante el empleo de recursos metalingüísticos para superar las anomalías y los desniveles lingüísticos, aunque el resto del vocabulario siga perteneciendo al lenguaje objeto. En ese sentido, el lenguaje se aplicaría como remedio a sí mismo gracias a sus componentes metalingüísticos. No es que el metalenguaje consista en una facultad general o en un sistema lingüístico, simplemente, estamos ante elementos metalingüísticos, combinados con elementos del lenguaje objeto, que se realizan en actos de habla individuales. Así pues, el metalenguaje no se identifica con el lenguaje técnico formalizado del lógico o del lingüista, ya que los usos metalingüísticos cotidianos (incluidos los metalenguajes del lógico o del lingüista) se distinguen por su reflexividad. 
Para Weinrich, la estructura reflexiva del lenguaje se pone de manifiesto implícitamente en los recursos gramaticales e indicaciones morfosintácticas que introducen instrucciones para la comprensión del lenguaje (el modo interrogativo, la negación, los marcadores discursivos concesivos, los tiempos verbales, etc.), pero también se despliega explícitamente el metalenguaje en algunos recursos lexemáticos que proveen signos metalingüísticos para reflexionar sobre el proceso comunicativo. De ese modo, la reflexión metalingüística sobre los supuestos del lenguaje no se sobrepone al lenguaje objeto como una formalización especializada o un lenguaje artificial; y es que los actos reflexivos metalingüísticos se despliegan en la comunicación cotidiana cada vez que se plantean diferencias de nivel en la competencia lingüística, dificultades de comprensión, ambigüedades gramaticales o imprecisiones en el vocabulario. En suma, el metalenguaje es solo un recurso de la reflexividad metalingüística inherente al lenguaje cotidiano, y resulta contraproducente el ideal lógico-lingüístico de reducir el lenguaje natural a una reflexividad sin lenguaje objeto (Weinrich, 1981, pp. 126-139).

La perspectiva lingüística según la cual el metalenguaje resulta inseparable de la propia realización del lenguaje abre la posibilidad de diferenciar las modalidades de reflexión metalingüística. En ese sentido, Eugenio Coseriu (1981) distinguió dos modos de metalenguaje, esto es, dos modos en que el lenguaje tiene por objeto el lenguaje primario (cuyos elementos designa, de la misma manera que el lenguaje primario designa la realidad extralingüística): el metalenguaje del discurso y el metalenguaje de la lengua. Según Coseriu, el metalenguaje del discurso corresponde a la posibilidad de convertir cualquier elemento del lenguaje primario en nombre de sí mismo, en virtud de un empleo metalingüístico del lenguaje (por ejemplo, al afirmar “Metalingüístico" es un adjetivo). Las expresiones de este metalenguaje del discurso son el resultado de la aplicación de reglas de metalexicalización propias de cada lengua y constituyen únicamente un repertorio ilimitado de nomenclaturas que carecen de la estructuración semántica de los términos del lenguaje natural primario (aunque algunos elementos del metalenguaje del discurso puedan integrarse en la semántica de la lengua primaria, como en el caso de un distingo o los peros). 
Por otra parte, el metalenguaje de la lengua corresponde a ese dominio de la estructura léxica de un determinado idioma que permite significar el lenguaje como ámbito de realidad y de experiencia mediante términos lingüísticos específicos y oposiciones semánticas determinadas (palabra, lengua, lenguaje, discurso, habla, etc.). Según Coseriu, la lingüística también constituiría un metalenguaje universal de carácter científico o una terminología metalingüística especializada (referente a la realidad objetiva del lenguaje), aunque sus delimitaciones conceptuales no coinciden con las distinciones metalingüísticas disponibles en cada idioma. En suma, no habría que confundir el metalenguaje del discurso con el metalenguaje de la lengua o con la terminología metalingüística de la ciencia del lenguaje (Coseriu, 1981, pp.107-109).

\section{El metalenguaje de la teoría}

Al caracterizar el ámbito de la semántica lingüística, John Lyons (1997) reconoció la importancia de disponer de un metalenguaje técnico y preciso para describir el lenguaje. En ese sentido, Lyons sostenía que las lenguas naturales disponen de un metalenguaje que les permite describir a otras lenguas, al lenguaje en general y a sí mismas y pueden cumplir esa función metalingüística precisamente en virtud de la propia reflexividad del lenguaje que permite que lo empleemos para referirse a sí mismo. Según Lyons, la adopción de un determinado idioma como metalenguaje involucra ciertas modificaciones en el vocabulario metalingüístico: o bien la restricción de su uso mediante definiciones adecuadas a los propósitos especializados, o bien la extensión del vocabulario cotidiano con términos técnicos no habituales. Desde el punto de vista de Lyons, aunque algunos lógicos y lingüistas han forjado metalenguajes formalizados para describir las lenguas naturales, se puede llevar a cabo esa tarea con un metalenguaje ordinario restringido y extendido. Así pues, el uso metalingüístico cotidiano de la lengua permite emplear la forma escrita ordinaria de una expresión para representar la palabra en sí misma, o bien para representar la forma o el significado de la palabra (Lyons, 1997, pp. 30-35). Por ejemplo, Lyons se sirve de la convención metalingüística del empleo de las comillas simples para las expresiones, de las cursivas para la forma oral o escrita y de las comillas dobles para representar los significados; se trata únicamente de una codificación y sistematización de las convenciones metalingüísticas del lenguaje cotidiano escrito. 
Por otra parte, el metalenguaje cotidiano del cual se sirve la semántica lingüística permite reformular las relaciones de referencia y denotación entre lenguaje y mundo; además de remitir a entidades, propiedades o agregados de primer orden —como es propio de la capacidad expresiva de las lenguas naturales-, se puede dar cuenta metalingüísticamente del modo en que se cosifican o hipostasian propiedades, relaciones, procesos, actividades y estados mediante un vocabulario de segundo orden y de recursos gramaticales empleados para la referencia de segundo orden (cuantificadores, determinantes, clasificadores, etc.) (Lyons, 1997, pp. 348-350). No obstante, aunque cada lengua natural implique un metalenguaje ordinario que puede ser empleado para los fines de la descripción lingüística, el metalenguaje cotidiano de cada lengua natural no equivale semánticamente a los de otras lenguas (como atestiguan las distintas relaciones semánticas de los términos lengua, langue o language) (Lyons, 1997, p. 43).

Dentro del marco de la lingüística sistémico-funcional, Halliday y Matthiessen (1999) también han argumentado que existe cierta continuidad entre el lenguaje (que nos permite disponer de recursos para construir nuestra experiencia del mundo) y, por otra parte, el metalenguaje de las teorizaciones semánticas y gramaticales (que aporta recursos para construir nuestra experiencia del lenguaje a través de un sistema semiótico). En ese sentido, Halliday y Matthiessen no solo conciben el metalenguaje como una vuelta reflexiva del lenguaje sobre sí mismo, sino que además remarcan la estratificación que caracteriza al metalenguaje en cuanto que sistema semiótico. En efecto, la construcción del lenguaje en términos teóricos abstractos se realiza mediante alguna forma de representación, que puede ser el mismo lenguaje en el discurso de la teoría, o bien alguna semiótica diseñada específicamente para ese propósito (algún formalismo lógico o gramatical); pero, asimismo, el metalenguaje de la teoría se realiza eventualmente en alguna implementación (como programas computacionales). En suma, el metalenguaje lleva a cabo la construcción teórica del lenguaje en diversos estratos (como la construcción teórica, la representación y la implementación) y se sirve de los recursos teóricos, representacionales y de implementación, a través de procesos como la descripción, la deducción o la compilación. 
En la construcción metalingüística del lenguaje, la semiótica representacional puede coincidir con el propio lenguaje (de modo que la teoría se represente discursivamente), o bien cabe recurrir a alguna semiótica representacional gráfica o diagramática. En todo caso, Halliday y Matthiessen concluyen que el mejor metalenguaje para construir el lenguaje es el lenguaje mismo, pues los sistemas semióticos formalizados solo logran la precisión a expensas de la cobertura (Halliday y Matthiessen, 1999, pp. 30-35).

En el contexto de la discusión sobre los universales lingüísticos, Anna Wierzbicka (2005) ha defendido la tesis de que la formulación de universales culturales o cognitivos, así como la apreciación de diferencias interculturales, presuponen una labor intelectual de generalización que ha de expresarse en algún lenguaje y, por tanto, requieren de un metalenguaje que aporte universales del lenguaje. No en vano, cada lengua incorpora marcos cognitivos y guiones culturales específicos, de manera que cualquier intento de reconocer universales a partir de una sola lengua natural corre el riesgo de imponer esas pautas inherentes como falsos universales e impide apreciar las diferencias culturales. En ese sentido, Wierzbicka concluye que la formulación de universales culturales o cognitivos se ha de plantear en un metalenguaje universal que posibilite generalizar sobre las distintas culturas de modo neutral. En la teoría del metalenguaje semántico natural (desarrollada por Wierzbicka desde los años setenta), se presupone que existe un núcleo de conceptos universales recogido en todos los lenguajes, de manera que la investigación lingüística empírica está en condiciones de identificar ese núcleo lingüístico y cognitivo universal que serviría como metalenguaje para describir los aspectos universales y las diferencias específicas entre las culturas humanas. En todo caso, según Wierzbicka (2005), este núcleo metalingüístico de conceptos universales no solo resulta accesible mediante el análisis semántico empírico riguroso, sino también gracias al testimonio de las personas bilingües y los migrantes de la lengua. 
El metalenguaje semántico natural, en cuanto que núcleo léxico y gramatical compartido por todas las lenguas naturales, se realizaría de modo específico en cada lengua natural; de ahí que solo pueda formularse como un lenguaje mínimo de conceptos universales empíricamente establecidos que se extrae de alguna lengua natural (por ejemplo, como un metalenguaje semántico natural del inglés, dada su difusión en la comunicación académica). Para Wierzbicka, el metalenguaje semántico natural permite comparar las categorías lingüísticas universales del espacio y del tiempo, los modelos lingüísticos y culturales de la persona, así como los guiones culturales, marcos normativos y comprensiones compartidas a través de distintas culturas lingüísticas. En ese sentido, la investigación en torno al metalenguaje semántico natural ha conseguido identificar todo un repertorio de conceptos universales elementales: algunos sustantivos (por ejemplo, cuerpo); determinantes (como este u otro); cuantificadores (como uno o algunos); atributos (como pequeño o bueno); predicados mentales (por ejemplo, pensar, ver o sentir); conceptos referidos al habla (decir, palabras); conceptos para acciones, eventos y movimientos (hacer, suceder o mover); conceptos relativos a la vida y la muerte (vivir, morir); conceptos lógicos (como no, porque o si); conceptos relativos al tiempo (cuando, ahora, después, etc.); conceptos referentes al espacio (donde, aquí, sobre, debajo, etc.); intensificadores (muchos, más), conceptos taxonómicos y de partes (clase de, parte de); o conceptos de semejanza (por ejemplo, como) (Wierzbicka, 2005, p. 259).

En suma, la investigación lingüística empírica a través de las distintas culturas pone de manifiesto todo un núcleo universal de recursos conceptuales sobre los cuales se sostienen tanto el entendimiento humano como la comunicación y comprensión interculturales. Se trata de un metalenguaje semántico natural en el que, incluso, cabría reconocer cierto conjunto de predicados psicológicos que articulan un modelo popular universal de la persona y de la mente (con rasgos existenciales, psicológicos, sociales y morales) a través de las articulaciones lingüísticas y modos de hablar que comparten todas las culturas. Según Wierzbicka (2005), solo mediante este metalenguaje semántico natural se daría la apremiante opción de compartir esquemas culturales y lograr una comprensión intercultural que preserve la diferencia específica de las culturas lingüísticas. 
En fin, además de la concepción del metalenguaje como lenguaje formalizado de orden superior que tiene al lenguaje natural como objeto, la investigación lingüística ha barajado una noción semántica de metalenguaje entendido como el repertorio translingüístico de recursos universales de la comunicación humana.

\section{El giro cognitivo hacia la metarrepresentación}

En el terreno de la pragmática cognitiva hace tiempo que circula cierto vocabulario de términos meta-prefijados, entre los cuales destaca el concepto de metarrepresentación; se trata de un término que expresa nítidamente una apuesta representacionista y cognitivista a la hora de concebir la comprensión del significado del hablante y los procesos de interpretación inferencial. Como argumentan Sperber y Wilson (2002), la pragmática cognitiva se enfrenta al problema crucial de que el significado oracional subdetermina el significado del hablante. Desde esa perspectiva, la interpretación pragmática se concibe como en un ejercicio de lectura de la mente que involucra la atribución inferencial de intenciones. No en vano la comunicación humana - ya sea verbal o no verbalimplica la expresión y reconocimiento de intenciones, de modo que la interpretación pragmática se perfilaría como un ejercicio de metapsicología en que el oyente infiere el significado intencionado del hablante a partir de evidencia que puede incluir la información lingüísticamente codificada en un enunciado. Aunque se ha querido ver en la interpretación pragmática un ejercicio de decodificación, Sperber y Wilson consideran que se trata de un proceso metapsicológico. No obstante, el proceso de interpretación no es una simple aplicación de capacidades genéricas de lectura de la mente en el dominio particular de la comunicación, como sostienen quienes atribuyen la labor a un procesamiento ejecutivo central y suponen largas cadenas de inferencias reflexivas. La interpretación pragmática se basaría en un módulo metacomunicativo de comprensión específico con principios y mecanismos propios: la lectura mental y la labor metarrepresentacional implicadas en la interpretación pragmática serían atribuibles al surgimiento evolutivo de un módulo de comprensión basado en la relevancia, es decir, en la maximización de la eficiencia cognitiva (Sperber y Wilson, 2002). Como se puede apreciar, la pragmática cognitiva sitúa las metarrepresentaciones y los procesos metacognitivos en el centro del conocimiento del hablante y de su competencia comunicativa. 
En la pragmática cognitiva, el concepto de metarrepresentación permite vincular los aspectos cognitivos, comunicativos, lingüísticos e, incluso, psicológicos del lenguaje humano. Para Sperber (1999), los sistemas cognitivos humanos se caracterizan no solo por su capacidad de construir y procesar representaciones de objetos y estados de cosas, sino también por la posibilidad de forjar representaciones de segundo orden, como representaciones mentales o lingüísticas. La inteligencia humana involucra la posibilidad de interpretar y predecir la conducta ajena al reconocer los estados mentales de otros, en la medida en que somos sistemas intencionales de segundo orden que tienen creencias y deseos sobre creencias y deseos. La capacidad humana de metarrepresentación nos convierte en psicólogos espontáneos que comprenden metacognitivamente los procesos cognitivos, atribuyen actitudes proposicionales y disponen de una teoría de la mente, ya sea mediante simulación o por inferencias basadas en evidencia (en virtud de cierta teoría de la teoría). Desde ese punto de vista, la capacidad de atribuir falsas creencias constituye un claro indicador de competencia metarrepresentacional. En suma, Sperber (1999) considera que, en cualquier acto comunicativo, se despliegan metarrepresentaciones de los participantes respecto a los estados mentales y significados intencionados. Por otra parte, los lenguajes humanos tienen recursos sintácticos y semánticos para operar como metalenguajes (por ejemplo, la citación directa o indirecta). Por lo demás, cabría pensar que la conciencia humana no consiste sino en la metarrepresentación reflexiva de los contenidos mentales en pensamientos de orden superior (Sperber, 1999).

En lo que concierne a los tipos de metarrepresentaciones, Sperber (2000) considera que podemos distinguir algunas categorías principales: las representaciones mentales de las representaciones mentales (por ejemplo, el pensamiento Juan cree que va a llover); las representaciones mentales de las representaciones públicas (como el pensamiento Juan dijo que va a llover); las representaciones públicas de las representaciones mentales (como la expresión Juan cree que va a llover); y las representaciones públicas de representaciones públicas (por ejemplo, la expresión Juan dijo que va a llover). 
Según Sperber, la mayoría de los estudiosos han estado predominantemente interesados en una sola categoría de metarrepresentación: los psicólogos de la teoría de la mente, por ejemplo, han estudiado las representaciones mentales de las representaciones mentales; los teóricos de la respuesta del lector, las representaciones mentales de las representaciones públicas; y los semiólogos, las representaciones públicas de representaciones públicas. Asimismo, se podrían diferenciar distintas capacidades metarrepresentacionales: junto a la capacidad metapsicológica estándar de leer la mente, los seres humanos pueden tener un módulo de comprensión dirigido a la interpretación en directo de los enunciados, así como un módulo lógico-argumentativo dirigido a persuadir a los demás y evitar el engaño (Sperber, 2000, pp. 3-7).

Por otra parte, Wilson (2000) plantea que las metarrepresentaciones lingüísticas varían tanto en grado de explicitud como en el tipo de original que representan, ya se trate de representaciones públicas (enunciados), representaciones mentales (pensamientos) o representaciones abstractas (proposiciones). Desde el punto de vista lingüístico, Wilson considera conveniente dar cuenta de los dispositivos metarrepresentacionales en el contexto de las capacidades metapsicológicas y metacomunicativas más generales. No en vano, el reconocimiento y la interpretación de metarrepresentaciones lingüísticas implica una sustancial cantidad de inferencia pragmática, así como presupone un procedimiento de comprensión (regido por la expectativa de relevancia) que podría constituir la base de una capacidad metacomunicativa modular y aportar un componente de la capacidad metapsicológica más general o teoría de la mente (Wilson, 2000). En fin, la pragmática cognitiva parece subsumir el metalenguaje en la capacidad metarrepresentacional más amplia de la mente humana. 


\section{La proliferación de metadiscursos}

En el ámbito de la teoría literaria, Gerard Genette (1989, originalmente publicado en 1962) introdujo el concepto de metatextualidad para designar uno de los modos en que tiene lugar la trascendencia transtextual de un texto en otros. Genette planteaba que el texto poético no ha de ser considerado únicamente en su singularidad, sino desde las modalidades generales de trascendencia textual (como los tipos de discurso, modos de enunciación y géneros literarios) de las cuales depende la realización de cada texto y que ponen a cada texto en relación con otros textos. Una de las formas más explícitas y concretas de remisión transtextual es la intertextualidad, definida como la incorporación de enunciados, fragmentos o textos breves en un determinado marco textual. Según Genette, la modalidad más explícita de intertextualidad consiste en la cita (entrecomillada y, eventualmente, acompañada de su referencia); menos explícitas y canónicas resultan el plagio y la alusión. Otra forma posible de transtextualidad se asocia al paratexto, esto es, al enmarcado de un texto con todo un sistema de elementos textuales (títulos, subtítulos, epígrafes, prefacios, epílogos, notas a pie de página, glosas, ilustraciones, etc.) que organizan y acotan la producción y recepción textuales. Por otra parte, la hipertextualidad caracteriza un tipo de interferencia transtextual en que un determinado texto (el hipotexto) se incorpora en otro (el hipertexto) por medio de una serie de transformaciones directas o indirectas, como la imitación, la parodia o el pastiche. Otra forma de transtextualidad que Genette mencionaba es la architextualidad, o sea, la inscripción más o menos explícita de un texto en algún tipo de repertorio textual o de género discursivo o literario, como la novela, la poesía, el ensayo, etc. En cuanto a la metatextualidad, consiste en un tipo de trascendencia transtextual en que un texto habla de otro sin citarlo e, incluso, sin nombrarlo. Genette consideró que la metatextualidad es particularmente característica de la relación crítica, en la cual se da implícitamente algún posicionamiento o comentario respecto a un texto ajeno (Genette, 1989, pp. 9-17).

En ese sentido, Genette caracterizaba la metatextualidad como la presencia de un texto de orden superior que habla de otro texto, pero también se refiere al metatexto crítico como si constituyese un género. 
A diferencia de otras formas explícitamente literarias de relación transtextual (como las transformaciones de unos textos en otros, por medio del pastiche o de la imitación satírica), el metatexto no suele ser ficcional. En todo caso, las formas de transtextualidad no constituyen categorías estancas, sino que se comunican y relacionan de manera determinada: puede ocurrir que una transformación architextual opere por medio de la imitación hipertextual y, además, se sirva de una marco paratextual que, a su vez, puede aportar indicios metatextuales (como Este libro es una novela); por otra parte, elementos paratextuales como el prólogo introducen ocasionalmente comentarios metatextuales, así como algunas transformaciones hipertextuales de corte paródico son ejercicios de comentario crítico en acción. Por lo demás, el comentario metatextual crítico depende en gran medida de la citación intertextual de apoyo (Genette, 1989, pp. 17-18).

Aparte del concepto de metatextualidad, en las últimas décadas hemos asistido a una proliferación tanto de los usos del significante metalenguaje como de diversos meta-vocabularios que pretenden dar cuenta de la reflexividad metalingüística. Al cartografiar el estado del arte sobre la reflexividad del lenguaje, John Lucy (1993) ilustraba una notable variedad de recursos mediante los cuales cada lenguaje puede emplearse reflexivamente para comunicar sobre el uso del propio lenguaje, ya sea a través de códigos lingüísticos diferenciados, o bien en un solo lenguaje que opera simultáneamente como medio y objeto de la comunicación. Cabe reconocer reflexividad lingüística en la referencia explícita a las regularidades del lenguaje o cuando se declaran abiertamente los actos de habla ejecutados. Pero también hay un uso reflexivo del lenguaje en el empleo de formas indexicales (cuya comprensión requiere considerar autorreferencialmente la instancia de la enunciación en que los enunciados adquieren significado), o bien en los nombres propios (que, carentes de contenido informativo, solo indican reflexivamente la existencia de una etiqueta convencionalmente codificada para referirse a un individuo) y en otros recursos que indican reflexivamente a los interlocutores cómo interpretar los enunciados y enmarcan la comprensión del discurso (las expresiones realizativas explícitas, el discurso referido, el desdoblamiento poético de la enunciación, las reordenaciones gramaticales del enunciado, etc.) (Lucy, 1993, pp. 9-11). 
Según Lucy (1993), el discurso cotidiano está tan marcado por la actividad reflexiva que podría decirse que el lenguaje es esencialmente reflexivo. Por otra parte, Lucy reforzaba esta percepción de la reflexividad inherente del lenguaje, en la medida en que su reconstrucción conceptual daba cuenta de múltiples enfoques del metalenguaje: los enfoques lógico-lingüísticos centrados en formas metalingüísticas especializadas o en un código de orden superior que permiten referirse a las proposiciones con contenido cognoscitivo del lenguaje objeto; los enfoques semióticos funcionales, centrados en las prácticas semióticas de la comunicación y en las formas de interacción social que resultan enmarcadas por la función metalingüística y metacomunicativa inherente a la actividad comunicativa; los estudios literarios que se centran en los efectos poéticos del discurso referido, en la capacidad del lenguaje reflexivo para recrear los contextos comunicativos y en el significado estético de las distintas formas de enmarcar y reportar las voces enunciativas (Lucy, 1993, pp. 11-21)

La importancia de la reflexividad metalingüística se extiende a los metalenguajes de las humanidades y las ciencias sociales, que se ven sistemáticamente enfrentadas a la difícil tarea de tomar conciencia de los recursos lingüísticos con que se describen los lenguajes y actividades comunicativas, así como al desafío de distinguir adecuadamente los marcos semióticos de los lenguajes teóricos y las prácticas semióticas de los actores sociales. En ese sentido, Lucy consideraba que hay mucho trabajo por realizar para diferenciar las modalidades funcionales del metalenguaje reflexivo (sin confundir los recursos metalingǘsticos con los usos del lenguaje objeto) y para distinguir adecuadamente la diversidad de funciones del lenguaje reflexivo (el metalenguaje explícito especializado, el discurso referido, la glosa del código comunicativo, etc.); asimismo, deberíamos explorar los límites borrosos del lenguaje reflexivo en el lenguaje cotidiano (no siempre marcados explícitamente mediante recursos metalingǘsticos) y dar cuenta de los empleos creativos del lenguaje reflexivo y de las formas en que la reflexividad del lenguaje permite trascender las limitaciones de los marcos metalingüísticos (Lucy, 1993, pp. 28-29). 
También Michael Silverstein (1993) ha argumentado que el lenguaje en uso y la praxis sociocultural de la interacción lingüística, así como la textualización de un lenguaje denotativo (referencial y predicativo), involucran diferentes modalidades de enmarcado metalingüístico. En la medida en que los textos representan acontecimientos $-\mathrm{y}$, específicamente, eventos de empleo del lenguaje-, todo texto incorpora un discurso metapragmático sobre dichos eventos, sobre la práctica discursiva y sus supuestos pragmáticos indexicales; pero, además, la pragmática del discurso resulta organizada, enmarcada y regimentada por toda una maquinaria de recursos metapragmáticos con distintos grados de explicitud. En ese sentido, la pragmática de la textualidad involucra relaciones indexicales entre los recursos semióticos y los contextos - y cotextos - en que acaecen, esto es, relaciones de presuposición (asunciones indexicales relativas a la adecuación al contexto) y de entrañamiento (implicaciones sobre la eficacia del enunciado en el contexto de la enunciación). Pero el acontecimiento social del empleo del lenguaje también conlleva cierta representación metapragmática que le atribuye determinada estructura cohesiva al discurso y, así, ordena la interacción discursiva como un texto interaccional organizado y dirigido a un propósito. De ese modo, las funciones semióticas indexicales de presuposición y entrañamiento (asociadas al funcionamiento pragmático del discurso) entran en relación dialéctica con la función metapragmática que enmarca los recursos semióticos indexicales y asunciones contextuales, como segmentos y episodios de un texto interaccional organizado y regimentado (Silverstein, 1993, pp. 33-38). No hay enunciación al margen de este enmarcado metapragmático.

Desdeesaperspectiva, Silverstein(1993)considerabaqueeldiscursometapragmático constituye una modalidad de metasemiosis que concierne a la dimensión pragmática e indexical del lenguaje, de la misma manera que la metasemántica es un modo metasemiótico relativo a la determinación estructural del sentido, y tiene lugar como una especificación del significado (por ejemplo, mediante la glosa definicional cotidiana). En todo caso, ya que la metasemántica proyecta la estructura lingüística en textos denotativos compuestos de oraciones significativas, puede sostenerse que constituye un tipo de enmarcado metapragmático específico con asunciones vinculadas a cierta perspectiva del texto interaccional. 
Al fin y al cabo, la metasemántica requiere cierta construcción textual de la interacción discursiva y presupone tanto la metasemántica virtual de las formas gramaticales como los recursos metasemánticos explícitos o las glosas cotidianas que enmarcan el sentido de las expresiones. Para Silverstein (1993), existen distintos grados de explicitud denotativa de los recursos metapragmaticos que enmarcan la semiosis pragmática: oscilan entre la explicitud denotativa y la realización de expresiones metapragmáticas en la estructura gramatical oracional y, por otra parte, la regimentación implícita de la semiosis pragmática operada en el texto interaccional, sin recurrir a formas denotativas explícitas instanciadas en elementos léxicos o expresiones gramaticales.

En ese sentido, las relaciones funcionales entre pragmática y metapragmática del discurso están sujetas a diversas modalidades de calibración metapragmática: en la calibración reflexiva, hay una coincidencia autorreferencial entre el recurso semiótico metapragmático y la regimentación pragmática del discurso (como ocurre en la configuración indexical poética); en la calibración informativa, el objeto de la metasemiosis se construye como un evento distinto del señalamiento metapragmático y se dispone de una contextualización del recurso metapragmático y del acontecimiento pragmático de la enunciación, en algún marco común reconocible (como sucede con las expresiones deícticas o los verbos realizativos); en la calibración nómica, la regimentación metapragmática de la pragmática del discurso remite a un ámbito epistémico distinto y tiene lugar mediante mecanismos de ritualización y autorización de la enunciación (como los marcadores evidenciales y modales o el discurso referido). Según Silverstein, este complejo proceso dialéctico entre la pragmática de la enunciación y la regimentación metapragmática del discurso no solo faculta el empleo e interpretación creativos del discurso; además, los recursos metapragmáticos encapsulan ideologías relativas al uso del lenguaje y posibilitan la instauración de mecanismos semióticos socioinstitucionales. En fin, desde el punto de vista metapragmático, la actividad metalingüística y metacomunicativa resulta indisociable del acontecimiento del discurso (Silverstein, 1993, pp. 38-55). 
En el ámbito de la lingüística aplicada y del análisis de discurso, se ha consolidado (desde los años ochenta) la noción de metadiscurso, que remite a las interacciones entre un texto y su productor, o bien a las relaciones entre los interlocutores. De ese modo, se reconoce decididamente que el empleo del lenguaje genera interacciones comunicativas y sociales, y se recogen algunas concepciones sociolingüísticas relativas a los planos de discurso, los marcos, la alineación discursiva y la metaconversación (en gran medida, como reacción ante el predominio tradicional de las visiones del lenguaje meramente denotativas). Una de las formulaciones más consistentes de la noción de metadiscurso se encuentra en Ken Hyland (2005), quien emplea el término para referirse al repertorio de expresiones textuales autorreflexivas que permiten negociar los significados interaccionales: los recursos metadiscursivos ayudan a que el locutor o escritor exprese su punto de vista y se involucre con los interlocutores o lectores, como miembros de cierta comunidad de discurso. En primera instancia, Hyland considera que todo discurso oral o escrito incorpora expresiones que hacen referencia al productor del texto, al receptor imaginado y al mismo texto en despliegue; se trata de expresiones que suministran indicaciones sobre los participantes, el tipo de discurso en construcción y el contexto comunicativo. Hyland caracteriza como metadiscurso a todas esas expresiones textuales que organizan explícitamente el discurso y el punto de vista del escritor hacia el contenido o la audiencia; estamos hablando de aspectos del texto que encauzan la interacción social, de manera que el metadiscurso se asocia a los modos de involucrarse social y comunicativamente. En ese sentido, el concepto de metadiscurso pone en primer plano los aspectos interpersonales del lenguaje, así como las formas en que tienen lugar el posicionamiento discursivo del locutor, el manejo de la intención comunicativa o la contextualización textual por parte de los interlocutores (Hyland, 2005, pp. 11-14).

A diferencia de otras perspectivas sobre este tópico, Hyland considera que no se puede reducir el metadiscurso a aquello que no aporta información del contenido, sino indicaciones de la presencia del autor. Al fin y al cabo, no hay una frontera nítida entre los aspectos proposicionales y metadiscursivos del texto, ya que los rasgos del lenguaje en uso son multifuncionales, de manera que un mismo recurso lingüístico puede operar como un término de contenido o como una indicación metadiscursiva. 
Por otra parte, las expresiones que funcionan metadiscursivamente en un texto pueden esbozar comprensiones compartidas y convenciones sociales, que no siempre resultan obvias para el analista (como ocurre, por ejemplo, en el caso de los matices del lenguaje diplomático) (Hyland, 2005, pp. 16-27). No en vano, Hyland propone un modelo del metadiscurso que se centra en la negociación de las interacciones en el texto: el metadiscurso proporciona recursos interpersonales para organizar coherentemente los textos, introducir la posición del productor del texto, anticipar la respuesta del interlocutor y enmarcar la relación con el contenido del discurso. Desde esa perspectiva, el metadiscurso genera una dinámica retórica contextualmente modulada, de modo que la interacción comunicativa involucra posicionamientos discursivos, perspectivas respecto al asunto del texto y a la audiencia comunicativa. Según Hyland, el metadiscurso hace posible que el productor del texto proyecte una comunidad contextual común y mundos sociales reconocibles; y es que, como discurso funcionalmente especializado, el metadiscurso permite involucrarse con los interlocutores, guía sus expectativas y los asiste a la hora de interpretar y evaluar el texto como una realización discursiva coherente, creíble y convincente, siempre en el escenario de ciertos contextos sociales y retóricos. Por eso, el metadiscurso no solo expresa posicionamientos personales y relaciones interpersonales, sino que además vincula el texto a todo un trasfondo de prácticas sociales y comprensiones culturales (Hyland, 2005, pp. 11-14).

En cuanto a los recursos lingüísticos contemplados en el modelo de Hyland, hay toda una categoría de elementos interactivos con que el locutor acomoda el texto a las expectativas retóricas de la audiencia y ayuda al interlocutor a guiarse en el texto: marcadores de transición entre oraciones, ya sea de adición, comparación o consecuencia (como además, del mismo modo, o por tanto); marcadores de actos y escenas discursivas (como para concluir); marcadores endofóricos, que remiten a otras partes del texto (por ejemplo, en el párrafo anterior); evidenciales, que basan la información en otras fuentes textuales (como según X); o glosas del código comunicativo y aclaraciones del significado proposicional (como en otras palabras). 
Asimismo, existe todo un repertorio de elementos metadiscursivos interaccionales que involucran al interlocutor en el texto, en la medida en que el productor del texto se posiciona personalmente, introduce comentarios y encauza las repuestas al texto: expresiones de reserva, que fomentan el diálogo (como quizá); reforzadores, que enfatizan la certeza y la posición concluyente (como de hecho); marcadores que expresan la actitud hacia el contenido (como desafortunadamente); automenciones que explicitan la voz del autor (como los pronombres de primera persona); o marcadores de compromiso, que forjan una relación de complicidad con el interlocutor (por ejemplo, como usted entenderá) (Hyland, 2005, pp. 48-54).

William J. Vande Kopple (2012) reduce la taxonomía del metadiscurso a seis categorías de expresiones: los conectores textuales, que explicitan la organización textual (como primero, consiguientemente, como se dijo antes, en cuanto a, etc.); las glosas del código, que clarifican el sentido de las expresiones textuales, así como las atenuaciones e intensificaciones del sentido de los términos (como así llamado o estrictamente hablando); los marcadores ilocucionarios, que patentizan los actos de habla que se ejecutan en un texto, así como los marcadores de fuerza ilocucionaria (por ejemplo, mitigadores como debo preguntarle o reforzadores como muy sinceramente); marcadores epistemológicos, que indican el punto de vista y el estatus epistémico de lo enunciado (atenuadores como quizá, expresiones enfáticas como sin duda, indicadores de la evidencia como según $X$, etc.); marcadores de actitud (como afortunadamente, lamento que, etc.); finalmente, comentarios, a través de los cuales se apela al interlocutor, se anticipan sus posibles reacciones (como en les sorprenderá que) o se recomienda cierta estrategia interpretativa (como en debería revisar el anterior capítulo) (Vande Kopple, 2012, pp. 38-40).

En suma, como Hyland (2005) argumenta, hay tres principios que guían la concepción del metadiscurso como sistema de significados opcionalmente realizados a través de recursos lingüísticos. En primer lugar, el metadiscurso es distinto de los aspectos proposicionales del discurso, ya que concierne a los modos de organizar el texto, los posicionamientos discursivos y las interacciones mediante el texto (aunque no se puedan separar nítidamente los aspectos proposicionales y los metadiscursivos, la organización autónoma del texto y su dimensión interactiva). 
En segundo lugar, el metadiscurso es siempre interpersonal, pues se refiere a los aspectos del texto que encarnan las interacciones entre el productor del texto y los interlocutores. Por último, el metadiscurso se refiere únicamente a las relaciones internas al discurso, es decir, a los aspectos interaccionales del discurso que organizan la coherencia del texto y permiten negociar las posiciones discursivamente asumidas (Hyland, 2005, pp. 37-48).

\section{Las sospechas del metalenguaje}

El análisis de discurso de inspiración sociolingüística le ha prestado bastante atención a la función metalingüística, en virtud de la cual el lenguaje se centra en el propio lenguaje - ya sea en el código subyacente, en la forma lingüística o en la propia situación comunicativa y en el curso de la conversación-; en ese sentido, se ha consolidado el concepto de metacomunicación para referirse a las distintas modalidades de comunicación sobre la propia comunicación, bajo la modalidad de comprobaciones y controles sobre el significado, sobre las formas lingüísticas o los canales de comunicación. Como Michael Stubbs (1987) argumentó, todo discurso exhibe una función metacomunicativa y despliega actos metacomunicativos que remiten a distintos mecanismos de control de la situación de habla: los mensajes sobre los canales de comunicación, para comprobar si se mantiene abierta la comunicación y para garantizar su fluidez; el control comunicativo ejercido al determinar quién habla, por cuánto tiempo y de qué modo se suceden los turnos; asimismo, la comprobación de que los mensajes han tenido una recepción adecuada y se han comprendido.

Desde el punto de vista de Stubbs, el metalenguaje constituye una forma específica de metacomunicación en la cual el lenguaje se refiere al propio lenguaje, de manera que los hablantes pueden referirse a entidades lingüísticas en cierto universo de discurso, comentar o corregir lo que dicen, distinguir el uso y la mención (mediante la ironía o la parodia) e, incluso, remitirse intertextualmente a otros textos. Ahora bien, el interés del análisis de discurso propuesto por Stubbs radica sobre todo en los actos metacomunicativos concretos que realizan funciones específicas en el curso de la conversación y orientan la producción, intercambio y recepción de los mensajes. 
Por ejemplo, en un formato de comunicación altamente sujeto al control de la enunciación, como es el caso de la enseñanza escolar, se registra todo un repertorio de actos de control metacomunicativo ejercidos por el docente: comentarios para captar o demostrar atención y, así, fomentar la recepción y respuesta; comentarios, solicitudes y preguntas para controlar la cantidad de habla o, incluso, para hacer callar; comentarios y preguntas para comprobar o confirmar la comprensión; resúmenes de lo dicho y lo discutido; definiciones o reformulaciones de lo dicho o de lo leído en algún texto; comentarios críticos que introducen valoraciones sobre lo dicho o escrito; correcciones directas o reiteraciones de la versión correcta; o bien las especificaciones del tema en discusión y la delimitación de la importancia temática. Y es que ese tipo de actos metacomunicativos y metacomentarios reflejan las posiciones de los interlocutores y enmarcan el propósito comunicativo; definen la situación y el formato de la relación comunicativa, así como expresan perspectivas sobre los derechos y la competencia conversacionales de los interlocutores. En fin, los actos metacomunicativos introducen formas de control de la enunciación mediante la estipulación de quién tiene derecho a controlar la conversación y, además, al reproducir lingüísticamente ciertos valores básicos socioculturales y relaciones de estatus (Stubbs, 1987, pp. 60-74).

Por otra parte, el análisis crítico del discurso se ha mostrado particularmente interesado en el metadiscurso, en la medida en que tiene efectos ideológicos decisivos en la constitución de sujetos y relaciones sociales, así como en la construcción y reproducción de órdenes discursivos. En ese sentido, Norman Fairclough (1993) ha abordado el metadiscurso como una manifestación de intertextualidad y considera que la intertextualidad está estrechamente vinculada a la problemática de la hegemonía social y política, ya que apunta a la capacidad de los textos para transformar productivamente textos previos o para reestructurar convenciones de discurso y géneros discursivos dados. Para Fairclough, la intertextualidad no faculta una productividad discursiva e innovación textual ilimitadas, ya que existen restricciones sociales y condicionamientos atribuibles a las relaciones de poder establecidas, aunque los procesos de intertextualidad pueden desafiar discursivamente las formas hegemónicas y contestar el orden del discurso que controla la enunciación (Fairclough, 1993, pp. 102-103). 
Si bien hay una intertextualidad inherente y constitutiva en cualquier texto o discurso (en la medida en que estos incorporan, reproducen y transforman elementos de otros órdenes de discurso), la intertextualidad puede hacerse manifiesta, cuando se concreta abiertamente en un texto, a través de la incorporación de segmentos de otros textos o discursos, mediante la incrustación del discurso en la matriz discursiva de otro o por medio de la combinación de distintos textos y tipos discursivos en un formato textual y discursivo emergente (Fairclough, 1993, pp. 117-118).

Entre las formas de intertextualidad manifiesta, no solo cabe hacer referencia al discurso referido (que representa diferencialmente las voces discursivas y puede reproducir cierta organización discursiva, la situación comunicativa o el tono y estilo enunciativo). También el metadiscurso constituye una forma de intertextualidad manifiesta en la cual el productor del texto distingue niveles textuales y se distancia de algún nivel del texto, como si fuera un texto ajeno. Según Fairclough, este distanciamiento metadiscursivo respecto a lo enunciado puede lograrse mediante diferentes recursos: expresiones de reserva o categorizaciones aproximativas (como posiblemente o un tipo de), atribución del enunciado a algún otro texto o convención discursiva (por ejemplo, según argumenta $X \mathrm{o}$ en términos científicos) o figurativa (como metafóricamente hablando), o bien paráfrasis y reformulaciones de expresiones. El efecto ideológico del metadiscurso se asocia - para Fairclough - a cierto posicionamiento externo del locutor respecto a su discurso, como si estuviera en una posición superior desde la cual puede controlar y manipular los enunciados. En ese sentido, cabría pensar que el metadiscurso impugna la idea de que las identidades sociales se constituyen posicionalmente dentro de determinados órdenes de discurso; sin embargo, el distanciamiento metadiscursivo también introduce la ilusión de un control pleno de la enunciación por parte del sujeto del discurso. En suma, la dialéctica entre constitución discursiva de la subjetividad y reestructuración subjetiva del discurso también afecta al metadiscurso, que no deja de introducir en el discurso paráfrasis interesadas o definiciones ideológicamente motivadas (Fairclough, 1993, pp. 122-123). 
En el terreno del análisis del discurso, la sospecha sobre los usos del metalenguaje se extiende incluso al uso del metalenguaje por parte del teórico del lenguaje o del propio analista del discurso. Theo van Leeuwen (2004) expresa una marcada reticencia frente a la concepción lógico-lingüística del metalenguaje como representación de orden superior o registro científico especializado, que permitiría formular la teoría del lenguaje objeto al dejar de lado la significación en la lengua natural y llevar a cabo la formalización de significantes exactos. Según van Leeuwen, el metalenguaje formalizado y la teorización formalista del lenguaje (en términos formales y reglas formalizables) resultan característicos de cierto trasfondo socio-histórico e institucional contemporáneo que consagra los procedimientos formales libres de contenido como modalidad privilegiada de organización social; sin embargo, la concepción formalista y descontextualizada del metalenguaje nos impide comprender que la función metalingüística resulta consustancial al empleo cotidiano del lenguaje (Leeuwen, 2004, pp. 107-108).

Al fin y al cabo — como argumenta van Leeuwen—, la metacomunicación atraviesa la comunicación cotidiana, de manera que el metalenguaje no es un recurso exclusivo de la teoría lingüística o la semiótica. Desde la perspectiva de van Leeuwen, el metalenguaje del analista de discurso constituye una recontextualización de la práctica lingüística, del mismo modo que toda representación lingüística recontextualiza las prácticas sociales de las cuales emerge. Como cualquier representación lingüística, el metalenguaje convierte lo que hacemos con el lenguaje en algo que parece existir por sí mismo, de manera que se genera una aparente estabilidad de las prácticas sociales, que son legitimadas diferencialmente a través de los distintos formatos de representación (Leeuwen, 2004, pp. 109-110).

En ese sentido — según van Leeuwen-, las construcciones metalingüísticas del teórico involucran cierta representación de los participantes, de las actividades, de las circunstancias espacio-temporales y de los recursos requeridos para la actividad social; pero, además, pueden añadir elementos como evaluaciones, propósitos o legitimaciones. Con frecuencia, los metalenguajes de la lingüística no dan cuenta de la actividad social del lenguaje, sino que proporcionan una representación descontextualizada, materialmente cosificada e instrumental del lenguaje en términos de procesos de transmisión carentes de agentes. 
De modo análogo, los metalenguajes del analista de discurso recontextualizan las prácticas discursivas sociales: oscilan entre la representación funcional de los participantes como roles institucionales y la referencia explícita a los participantes; entre la terminología descontextualizada y la descripción de elementos contextuales específicos; entre la impersonalización y la autonomización del enunciado, como si este tuviera iniciativa propia y agencia; entre la terminología formal y las descripciones funcionales. No es de extrañar que los metalenguajes del analista del discurso representen a menudo los actos semióticos en términos de conducta instrumental y objetiven el contenido semiótico del lenguaje, como si las actividades discursivas fuesen solo de medios de intercambio o efectos mecánicos. A veces, los metalenguajes del analista privilegian la forma lingüística y presentan un agente que se sirve instrumentalmente de los recursos formales del lenguaje para hacer algo; otras veces, la iniciativa de los participantes se deja de lado, y se suministra una representación netamente funcional en que las formas lingüísticas cobran iniciativa y operan como agentes de procesos de expresión determinados (Leeuwen, 2004, pp. 113-127).

Ahora bien —según van Leeuwen-, una relación fructífera del análisis del discurso con el metalenguaje implica asumir que la metacomunicación se despliega usualmente a través de toda la comunicación cotidiana, de modo que habría que devolver los metalenguajes del analista al trasfondo de la vida social, donde se gestan las genuinas necesidades y problemas sociales. De ese modo, aunque los términos formales desempeñen un importante papel en la reformulación de los usos sociales del lenguaje, las representaciones metalingüísticas del analista no se han de restringir a dar cuenta de la forma lingüística, sino que han de incorporar las funciones y los significados asociados a nuestras prácticas discursivas. En fin, el metalenguaje no puede ser atesorado por los especialistas teóricos ni ha de limitarse a la descripción de los lenguajes que circulan en sociedad, sino que ha de comprometerse con el entramado sociosemiótico de prácticas lingüísticas de las cuales forma parte (Leeuwen, 2004, pp. 128-129). 


\section{A modo de conclusión: la dispersión del léxico meta-metalingüístico}

Si recapitulamos algunos de los principales desarrollos de nuestra historia conceptual de los metalenguajes, se puede reconocer, en primera instancia, cierta oscilación entre las conceptualizaciones del metalenguaje como un lenguaje de orden superior o un código metalingüístico formalmente escindido del lenguaje objeto y, por otra parte, aquellas concepciones del metalenguaje que consideran la función metalingüística como un recurso consustancial e inherente al discurso cotidiano y a los procesos de comunicación en el lenguaje natural. En ese sentido, podría sostenerse que existe cierto conflicto metalingüístico sobre los metalenguajes, que no es solo una discusión epistemológica sobre las posibilidades de formalización de un metalenguaje capaz de fundamentar las ciencias del lenguaje o una disputa sobre los recursos intrínsecos del lenguaje natural para reflexionar sobre sí mismo; también involucra un cuestionamiento crítico de la posición discursiva desde la cual se enuncia el metalenguaje y de las formas de distanciamiento reflexivo que garantizan la autoridad del enunciador del metalenguaje. Desde ese punto de vista, no hay teorización del metalenguaje que no implique cierta reflexión meta-metalingüística a través de la cual se deciden los significados de la meta-terminología de la ciencia del lenguaje, es decir, el empleo de términos como metalenguaje, metadiscurso, metacomunicación, metarrepresentación, etc. Ahora bien, en la medida en que esa reflexión meta-metalingüística se sirve de los recursos semióticos del discurso cotidiano, no hay que suponer que existe una jerarquía lógica de metalenguajes formalmente separados; simplemente, se trata de una selección reflexiva y una negociación discursiva de los recursos semióticos que permiten significar las dimensiones metalingüísticas del discurso.

En términos generales, se puede sostener — con Lucy (1993) - que los intentos de dar cuenta de la reflexividad metalingüística caen bajo ciertas categorías: los enfoques lógico-lingüísticos del metalenguaje centrados en la formalización semántica, los enfoques semióticos funcionales de la metacomunicación como enmarcado de la interacción discursiva y, por último, los enfoques centrados en la reflexividad poética que hace posible los efectos metatextuales e intertextuales del lenguaje literario. 
No obstante, nuestra revisión teórica nos ha permitido reconocer otros enfoques descriptivos del metalenguaje en la ciencia del lenguaje contemporánea: en primer lugar, la perspectiva cognitiva que subsume el metalenguaje bajo los mecanismos mentales de metarrepresentación (Sperber, 2000; Wilson, 2000); por otra parte, el enfoque descriptivo de la semántica universal, según el cual existe un metalenguaje semántico natural que aporta un repertorio translingüístico neutral de recursos conceptuales compartidos que posibilitan la comunicación intercultural (Wierzbicka, 2005). Como se puede apreciar, en la ciencia del lenguaje contemporánea se despliega un complejo arco de posibles perspectivas de la reflexividad metalingüística, de modo que el metalenguaje puede ser abordado desde el punto de vista de la semántica formal, la semiótica funcional, la semántica natural, la pragmática cognitiva, la pragmática del discurso y la semiótica del texto. En cada enfoque, tienen mayor o menor peso cada una de las dimensiones constitutivas del sistema de significación del lenguaje: la función representacional que organiza nuestra experiencia del mundo, la función interpersonal de negociación social del significado o la función textual de preservación de la coherencia y cohesión del texto.

Esta diferencia de enfoques sobre el metalenguaje se traduce en una notable dispersión de los usos del vocabulario metalingüístico. El concepto de metalenguaje puede designar distintos aspectos lingüísticos: un lenguaje de orden superior formalmente escindido del lenguaje natural; un nivel lógico del lenguaje que permite coordinar los usos lingüísticos y su referencia; una función del lenguaje cotidiano que posibilita comunicar sobre el código, así como glosar y traducir los significados; elementos léxicos y morfosintácticos del lenguaje natural que facultan la reflexión para aclarar malentendidos y ambigüedades en el discurso cotidiano; un metadiscurso que designa reflexivamente los elementos del lenguaje; una metalengua conformada por las construcciones y léxico de una lengua que significan la realidad del lenguaje; o bien un repertorio semántico natural de conceptos universales realizados léxica y gramaticalmente en todos los idiomas. 
A esta dispersión de significados del vocabulario metalingüístico, hay que añadir otras denominaciones que intentan dar cuenta de la reflexividad del lenguaje: la metacomunicación, en cuanto que comunicación sobre las pautas de interacción comunicativa; la metarrepresentación, como representación de representaciones mentales y representaciones lingüísticas públicas, que enmarca cualquier proceso de comprensión comunicativa; el metatexto, como modo de remisión transtextual en que un texto incorpora la mención y comentarios de otros textos; los recursos metapragmáticos, que permiten enmarcar los recursos semióticos del discurso en función de las indicaciones y asunciones contextuales, o bien del propósito textual; y el metadiscurso, como repertorio de recursos textuales que permiten la expresión de puntos de vista, el posicionamiento de los interlocutores y la negociación interpersonal del significado.

Tal vez pueda sistematizarse esta dispersión de los léxicos meta-metalingüísticos, si consideramos su distribución en una matriz que comprende las dimensiones del lenguaje que privilegia la reflexividad lingüística $\mathrm{y}$, por otra parte, los enfoques lingüísticos en los cuales se inscribe el vocabulario metalingüístico, como se aprecia en la tabla 1:

\begin{tabular}{|c|c|c|c|}
\hline \multirow{2}{*}{ enfoque lingüístico } & \multicolumn{3}{|c|}{ dimensión del lenguaje } \\
\hline & representacional & interpersonal & textual \\
\hline semántica formal & metalenguaje & & \\
\hline semántica natural & metalenguaje & & \\
\hline \multirow[b]{2}{*}{ semiótica funcional } & \multicolumn{3}{|c|}{ función metalingüística } \\
\hline & $\begin{array}{l}\text { metalenguaje de la } \\
\text { lengua }\end{array}$ & & $\begin{array}{l}\text { metalenguaje del } \\
\text { discurso }\end{array}$ \\
\hline \multirow[b]{2}{*}{$\begin{array}{l}\text { pragmática del } \\
\text { discurso }\end{array}$} & \multicolumn{3}{|c|}{ reflexividad metalingüística } \\
\hline & & \multicolumn{2}{|c|}{$\begin{array}{l}\text { metacomunicación } \\
\text { enmarcado metapragmático } \\
\text { metadiscurso }\end{array}$} \\
\hline pragmática cognitiva & \multicolumn{3}{|c|}{ metarrepresentación } \\
\hline semiótica del texto & & & metatexto \\
\hline
\end{tabular}

Tabla 1: Vocabulario metalingüístico presente en la ciencia del lenguaje 


\section{Referencias}

Agustín de Hipona. (2003). El maestro o Sobre el lenguaje. Madrid: Trotta.

Bateson, G. (1991). Una teoría del juego y de la fantasía. En Pasos hacia una ecología de la mente (pp. 205-221). Buenos Aires: Planeta-Carlos Lohlé.

Bochenski, I. M. (1985). Historia de la lógica formal. Madrid: Gredos.

Coseriu, E. (1981). Principios de semántica estructural (Segunda edición). Madrid: Gredos.

Fairclough, N. (1993). Discourse and social change. Cambridge: Polity Press.

Genette, G. (1989). Palimpsestos. Madrid: Taurus.

Halliday, M. A. K., y Matthiessen, C. M. I. M. (1999). Construing experience through meaning. A language-based approach to cognition. New York: Continuum.

Hjelmslev, L. (1971). Prolegómenos a una teoría del lenguaje. Madrid: Gredos.

Hyland, K. (2005). Metadiscourse. Exploring interaction in writing. London: Continuum.

Jakobson, R. (1988). El metalenguaje como problema lingüístico. En El marco del lenguaje (pp. 81-91). México, D. F.: Fondo de Cultura Económica.

Lucy, J. A. (1993). Reflexive language and the human disciplines. En J. A. Lucy (Ed.), Reflexive language. Reported speech and metapragmatics (pp. 9-32). Cambridge: Cambridge University Press.

Lyons, J. (1997). Semántica lingüiśtica. Barcelona: Paidós. 
Silverstein, M. (1993). Metapragmatic discourse and metapragmatic function. En J. A. Lucy (Ed.), Reflexive language. Reported speech and metapragmatics (pp. 33-58). Cambridge: Cambridge University Press.

Sperber, D. (1999). Metarepresentation. En R. A. Wilson y F. C. Keil (Eds.), The MIT encyclopaedia of cognitive sciences (pp. 541-542). Cambridge: The MIT Press.

Sperber, D. (Ed.). (2000). Metarepresentations. Oxford: Oxford University Press.

Sperber, D., y Wilson, D. (2002). Pragmatics, modularity and mind-reading. Mind and Language, 17(1-2), 3-23.

Stubbs, M. (1987). Análisis del discurso. Análisis sociolingüístico del lenguaje natural. Madrid: Alianza Editorial.

Tarski, A. (2005). La concepción semántica de la verdad y los fundamentos de la semántica. En L. M. Valdés Villanueva (Ed.), La búsqueda del significado. Lecturas de filosofía del lenguaje (Cuarta edición, pp. 299335). Madrid: Tecnos.

Unamuno, M. (2007). Obras completas, VIII. Ensayos. Madrid: Fundación José Antonio de Castro.

Van Leeuwen, T. (2004). Metalanguage in social life. En A. Jaworski, N. Coupland y D. Galasinski (Eds.), Metalanguage: Social and ideological perspectives (pp. 107-130). New York: Mouton De Gruyter.

Vande Kopple, W. J. (2012). The importance of studying metadiscourse. Applied Research in English, 1(2), 37-44.

Weinrich, H. (1981). De la cotidianidad del metalenguaje. En Lenguaje en textos (pp. 110-139). Madrid: Gredos. 
Wierzbicka, A. (2005). Empirical universals of language as a basis for the study of other human universals and as a tool for exploring cross-cultural differences. Ethos, 33(2), 256-291.

Wilson, D. (2000). Metarepresentation in linguistic communication. En D. Sperber (Ed.), Metarepresentations (pp. 411-448). Oxford: Oxford University Press. 